\title{
Editorial Challenges for Neonatology and Neonatologists
}

\section{Avroy F. Fanaroff, MD}

The rapid approach of the next century presents many challenges for the leaders of the rapidly maturing field of neonatal-perinatal medicine. These include the formidable task of luring the most highly qualified individuals into the subspecialty, training the correct number of neonatologists to meet the ever shifting market demands, and developing appropriate training for medical students, pediatric residents, and uconatal-perinatal medicine subspecialty residents. I would like to briefly address these three issues.

Currently, more than half of the trainees in neonatal-perinatal medicine programs are international medical graduates. Indeed, the United States has been fortunate to have attracted some of the top graduates from all continents into fellowship training; in addition, many now serve as program directors and faculty at leading medical centers and universities throughout the country. Legislation is closing the doors to these talented individuals, and we must redouble our efforts to direct the outstanding U.S. medical students into pediatrics and neonatal-perinatal medicine in particular. This necessitates familiarizing the students early in their careers with the nurseries and neonatal research laboratories and with the associated career opportunities in neonatal-perinatal and developmental medicine. Minimal investments in these students can yield huge dividends.

The neonatology workforce issue is a controversial topic. In 1985, the American Academy of Pediatrics (AAP) Committee of Fetus and Newborn made recommendations regarding the predicted workforce requirements for physicians practicing in the field of neonatal-perinatal medicine. ${ }^{1}$ At that time, there were 1346 sub-board-certified neonatologists and 300 other physicians identified as devoting fulltime to the care of newborn infants. The committee predicted the future need to be $<1500$ additional neonatologists. The 1999 United States Neonatologists and Perinatologists directory lists $>3500$ practicing neonatologists. ${ }^{2}$ There is also an army of neonatal nurse practitioners. The perception thus persists that there are too many neonatologists. Conversely, the dynamic changes in the delivery of health care and the changing role of the neonatologists, because general pediatricians have deserted even the well-baby nurseries, have resulted in a significant discrepancy between projected requirements and the current neonatology workforce and service responsibilities. ${ }^{3}$ Furthermore, there has been a movement away from the subspecialty delivery of health care exclusively at academic centers. The many care sites diffuse available resources and tend to increase workforce requirements but render it impossible to accurately predict the workforce needs..$^{3-5}$ Therefore, we should direct our attention to upgrading the quality of training and developing benchmarks to assess the quality of neonatalperinatal healthcare delivery. ${ }^{6}$

Education must be goal-oriented and goal-based. We must recognize that trainees at all levels learn by doing, not by listening and observing. Medical students, residents, and fellows learn better from hands-on experience. Knowledge comes from repeating the experience. It is time to develop multimedia-based interactive training modules that provide really good simulations of possible experiences in a manner similar to the training and recertification of airline pilots. Providing interesting experiences will improve motivation and enhance learning. This has been accomplished with some of the neonatal resuscitation modules. ${ }^{7}$ Resources need to be pooled so that the wheel is not constantly rediscovered, and we must be postured to avail ourselves of the educational resources from the Internet. As the technology rapidly advances, the patient simulations, including the sights and sounds, will make these virtual situations very real and will provide trainees with the opportunity to err without harming the patients. According to an old Chinese proverb "I hear and I forget; I see and I remember; I do and I understand."

Set goals for active learning, look for means of being original and imaginative. Let us be aware of the joy of teaching and recognize how extraordinarily rewarding an experience it can be to teach. Encourage trainees to recognize their role as teachers and ensure that they develop specific teaching and managerial skills. This way, the future of the subspecialty will be assured.

\section{References}

1. American Academy of Pediatrics, Committee on Fetus and Newborn. Manpower needs in neonatal practice. Pediatrics 1985;76:132-5.

2. Section on Perinatal Pediatrics, American Academy of Pediatrics. United States Neonatologists and Perinatologists Directory 1999. Elk Grove Village, IL: American Academy of Pediatrics; 1999.

3. Pollack, LD, Ratner IM, Lund GC. United States neonatology practice survey: personnel, practice, hospital and NICU characteristics. Pediatrics 1998;101:398405 .

4. Hall RT. Neonatal manpower needs: the writing's on the wall: we should read it and heed it. J Perinatl 1997;17:423-4.

5. Wirtschafter DD. Perinatal services in the era of managed care: a Kaiser Permanente physician's perspective. J Perinatol 1995;15:414-17.

6. Phibbs CS, Bronstein, JM, Buxton F, Phibbs RH. The effects of patient volume and level of care at the hospital of birth on neonatal mortality. JAMA 1996;276: 1054-9.

7. Bloom RS, Cropley C. Textbook of Neonatal Resuscitation. American Academy of Pediatrics, American Heart Association; 1996. 